\title{
Rancang Bangun Sistem Virtual Reality Nirkabel Berbasis WLAN
}

\author{
Muh Dimas Ariyantoํㅜ, Ahmad Wahyu Purwandi², Moh Abdullah Anshori ${ }^{3}$ \\ 1,3 Program Studi Jaringan Telekomunikasi Digital, \\ Jurusan Teknik Elektro, Politeknik Negeri Malang, Indonesia \\ ${ }^{2}$ Program Studi Teknik Telekomunikasi, \\ Jurusan Teknik Elektro, Politeknik Negeri Malang, Indonesia \\ 1riyan.gendut@gmail.com, ${ }^{2}$ purwandi2@gmail.com, ${ }^{3}$ anshori_ma@yahoo.com
}

\begin{abstract}
Virtual Reality technology is one of the technologies that currently growing and gaining interest, due to its wide application potential in multiple fields. Virtual Reality is a technology that allows a user interact with computer as well as other users through a virtual environment that replicates natural human senses, in this case encompassing hearing and sight. This research would explore design, realisation, and analysis of a wireless Virtual Reality system based on WLAN, using widely available hardware that is smartphone device. Practical implementation with widely available technology is prioritised compared to overall quality provided by the system. Operating system used for the PC is Microsoft Windows 10, and for smartphone Android version 6.0.1 is used as base. XAMPP distribution is used as HTTP server on top of Windows operating system on PC. Stereoscopic/360 degree MP4 video format is chosen as streaming load. The designed Virtual Reality system is capable of using hotspot capability of a smartphone to perform streaming of stereoscopic video with 1080s and 720s resolution. The designed room dimension is up to $6 x 4$ meter for a single transceiver configuration, and up to $6 x 8$ for two transceiver configuration. These dimension limitation is based on -3dB signal power drop that occurs at 5 meter distance in the performed test, as such the furthest distance between a transceiver and a client must be within 5 meter.
\end{abstract}

Keywords: Virtual Reality, WLAN, Video, Streaming, Smartphone.

Abstrak - Teknologi Virtual Reality merupakan salah satu teknologi yang semakin berkembang dan diminati pada saat ini, dikarenakan potensi penerapannya yang sangat luas pada berbagai bidang. Teknologi Virtual Reality merupakan teknologi yang memungkinkan manusia berinteraksi dengan komputer maupun dengan manusia lain melalui lingkungan virtual yang meniru indra manusia secara alamiah, dengan kata lain mencakup penglihatan dan pendengaran. Penelitian ini membahas perancangan, realisasi, serta analisis sebuah sistem Virtual Reality nirkabel dengan berbasis WLAN, menggunakan perangkat keras yang tersedia pada masyarakat yakni perangkat smartphone. Mengutamakan penerapan praktis dengan teknologi yang tersedia pada masyarakat dibandingkan kualitas keseluruhan sistem. Sistem operasi yang digunakan adalah Microsoft Windows 10 untuk PC dan Android versi 6.0.1 untuk smartphone. Menggunakan distribusi XAMPP pada PC/laptop Windows sebagai server HTTP. Media yang digunakan berupa video 360\%/stereoskopik berformat mp4. Sistem Virtual Reality yang dirancang mampu menggunakan hotspot smartphone untuk melakukan streaming pada resolusi 1080s serta 720s. Rancangan luas ruangan yang dibuat adalah hingga 6x4 meter untuk konfigurasi dengan satu pemancar, dan hingga 6x8 meter untuk konfigurasi dengan dua pemancar. Batasan ukuran ruangan ini didasarkan pada titik penurunan kekuatan sinyal sebesar -3dB yang terjadi pada jarak 5 meter pada kedua resolusi, sehingga batasan jarak terjauh antara klien dan server adalah 5 meter.

Kata kunci: Virtual Reality, WLAN, Video, Streaming, Smartphone.

\section{PENDAHULUAN}

Perkembangan teknologi akan selalu berjalan seiring dengan waktu, membuka potensi dan lapangan perkembangan yang belum pernah dibayangkan sebelumnya. Hal ini terutama terjadi pada perkembangan teknologi informasi dan komunikasi, dengan kemampuan untuk memproses dan menyampaikan informasi melalui media yang semakin beraneka ragam, serta sistem komunikasi yang semakin kompleks.

Teknologi Virtual Reality merupakan salah satu teknologi yang semakin berkembang dan diminati pada saat ini, dikarenakan potensi penerapannya yang sangat luas pada berbagai bidang. Teknologi Virtual Reality merupakan teknologi yang memungkinkan manusia berinteraksi dengan komputer maupun dengan manusia lain melalui lingkungan virtual yang meniru indra manusia secara alamiah, dengan kata lain mencakup penglihatan dan pendengaran.

Namun, masih banyak kendala dan keterbatasan yang dialami oleh sistem Virtual Reality modern. Salah satunya adalah mahalnya sistem Virtual Reality akibat biaya pengembangan dan eksperimentasi [1]. Akibatnya, sistem Virtual Reality sebagai medium hiburan hanya dapat dinikmati sebagian masyarakat, dan aplikasi pada bidang pendidikan menjadi sulit untuk dilakukan. Padahal, aplikasi pada bidang pendidikan memiliki potensi pengembangan dan pangsa pasar yang sangat luas, dan akan memungkinkan revolusi medium pembelajaran pada berbagai tingkat pendidikan.

Dengan demikian, dibutuhkan sebuah solusi untuk membangun sebuah sistem Virtual Reality yang terangkau oleh 
masyarakat. Salah satu cara untuk melakukannya adalah dengan menggunakan perangkat dan teknologi yang sudah tersebar luas di masyarakat, semisal perangkat smartphone. Dengan menggunakan perangkat smartphone yang telah tersebar luas di masyarakat bahkan di kalangan pelajar, biaya yang dibutuhkan untuk mengakses teknologi Virtual Reality dapat ditekan dengan cukup besar.

Pada konferensi Google I/O 2015 meluncurkan spesifikasi untuk sistem virtual reality Google Cardboard berupa platform untuk mengembangkan aplikasi serta spesifikasi perangkat headset dan lensa [2].

Selain itu, sistem Virtual Reality yang ada saat ini kurang cocok terutama pada aplikasi yang ditujukan untuk anak-anak yang cenderung bergerak kesana-kemari, akibat keterbatasan dari kabel yang digunakan untuk transfer data maupun daya pada perangkat, sehingga mempersempit potensi penerapan Virtual Reality itu sendiri.

Penelitian ini membahas perancangan, realisasi, serta analisis sebuah sistem Virtual Reality nirkabel dengan berbasis WLAN, menggunakan perangkat keras yang tersedia pada masyarakat yakni perangkat smartphone.

\section{METODE}

A. Tahap Penelitian

Adapun tahap penelitian yang akan ditunjukan dalam Gambar 1.

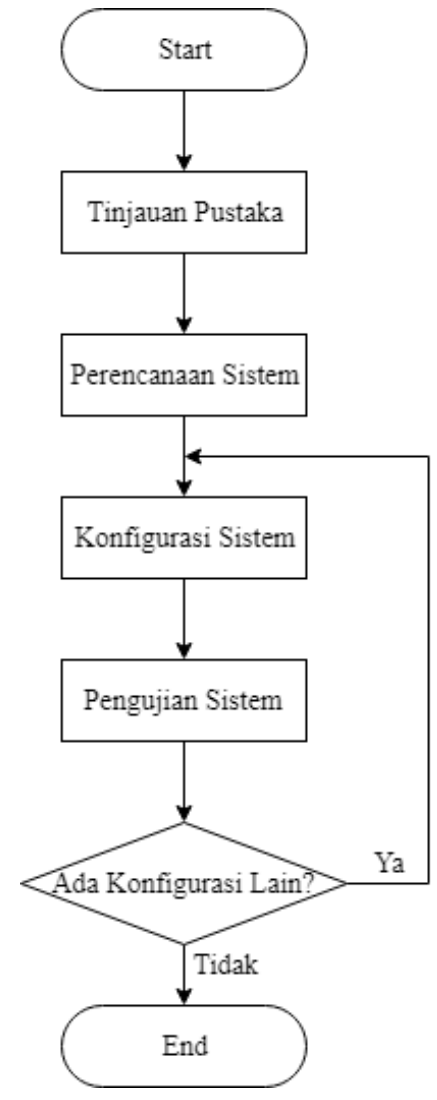

Gambar 1. Diagram Alur Tahap Penelitian

1. Penelitian dimulai dengan studi literatur tentang penelitian sebelumnya, serta teori pendukung dalam penyusunan penelitian ini diantaranya teknologi WLAN, sistem operasi Android, sistem server HTTP XAMPP, serta sistem monitor jaringan Wireshark.

2. Kemudian direncanakan konfigurasi sistem, yakni laptop dengan XAMPP sebagai server HTTP, Wireshark sebagai monitor lalu-lintas jaringan, serta menggunakan aplikasi berbasis Android sebagai client untuk melakukan stream.

3. Sistem yang telah direncanakan dan dikonfigurasi kemudian diuji untuk menentukan batasan-batasan sistem, dalam penelitian ini adalah throughput, delay, dan cakupan sinyal.

4. Hasil pengujian kemudian digunakan untuk melakukan perencanaan dan perancangan sistem kembali, dengan menerapkan batasan yang telah ditentukan dalam pengujian

\section{B. Alat dan Bahan}

1. Perangkat lunak yang digunakan pada penelitian ini ditunjukan dalam tabel berikut.

TABEL I

DAFTAR PERANGKAT LUNAK

\begin{tabular}{ll}
\hline \multicolumn{1}{c}{ Nama Bahan } & \multicolumn{1}{c}{ Keterangan } \\
\hline XAMPP & $\begin{array}{l}\text { Digunakan sebagai HTTP Host agar berkas pada } \\
\text { server dapat diakses oleh jaringan }\end{array}$ \\
\hline Wireshark & $\begin{array}{l}\text { Digunakan untuk mengumpulkan dan } \\
\text { menganalisa data }\end{array}$ \\
\hline Google Android & $\begin{array}{l}\text { Digunakan sebagai titik akses WLAN serta } \\
\text { sebagai sistem operasi klien untuk mengakses } \\
\text { berkas pada server. }\end{array}$ \\
\hline VR 3d Movie Player & Digunakan sebagai perangkat lunak klien stream. \\
\hline WiFi Analyzer & $\begin{array}{l}\text { Digunakan untuk mengumpulkan dan } \\
\text { menganalisa data. }\end{array}$ \\
\hline
\end{tabular}

2. Perangkat keras yang digunakan pada penelitian ini ditunjukan dalam Tabel berikut.

TABEL II

DAFTAR PERANGKAT KERAS

\begin{tabular}{ll}
\hline \multicolumn{1}{c}{ Nama Alat } & \multicolumn{1}{c}{ Keterangan } \\
\hline $\begin{array}{l}\text { Personal Computer }(\mathrm{PC}) \text { atau } \\
\text { Smartphone Android }\end{array}$ & $\begin{array}{l}\text { Sebagai perangkat keras server } \\
\text { penampung data serta sistem perekaman } \\
\text { data hasil penelitian. }\end{array}$ \\
& $\begin{array}{l}\text { Sebagai perangkat keras klien dan titik } \\
\text { akses WLAN, sebagai platform untuk } \\
\text { menjalankan dan melakukan pemrosesan } \\
\text { sistem Virtual Reality beserta input sensor } \\
\text { dll. }\end{array}$ \\
\hline Smartphone Android & $\begin{array}{l}\text { Sebagai perangkat keras pengukuran } \\
\text { sinyal. }\end{array}$ \\
\hline Router ZTE F609 & Sebagai perangkat keras titik akses \\
& WLAN. \\
\hline Google Cardboard set & Sebagai frame untuk menempatkan \\
& Smartphone yang dilengkapi bersudut \\
lebar.
\end{tabular}

\section{Teknik Pengumpulan Data}

Data-data yang digunakan dalam penelitian ini antara lain delay dan throughput jaringan ketika dilakukan streaming media Virtual Reality berupa video dan audio antara server/host komputer laptop dan client berupa aplikasi smartphone Android. Data yang juga diukur adalah kekuatan sinyal dari jaringan WLAN ketika streaming media virtual reality dilakukan.

Transmission Control Protocol/Internet Protocol (TCP/IP), jika diterjemahkan adalah Protokol Kendali Transmisi/Protokol Internet, adalah gabungan dari protokol TCP (Transmission Control Protocol) dan IP (Internet Protocol) sebagai sekelompok protokol yang mengatur komunikasi data dalam proses tukar menukar data dari satu komputer ke komputer lain di dalam jaringan internet untuk memastikan pengiriman data sampai ke alamat yang dituju [3]. 
Delay rata-rata antar paket dalam sebuah transmisi dapat dihitung dengan persamaan berikut:

$$
\text { Delay }=\frac{T_{\text {total }}}{n_{\text {paket }}}
$$

Keterangan :

$\mathrm{T}_{\text {total }}=$ Jumlah total waktu transmisi (sekon)

$\mathrm{n}_{\text {paket }}=$ Jumlah total paket yang ditransmisikan

Throughput adalah kecepatan rata-rata data ditransmisikan dalam suatu jaringan, dinyatakan dengan satuan baud atau bit per sekon. Secara umum, throughput yang lebih tinggi dianggap lebih baik, namun pada penelitian ini selama throughput berada lebih tinggi daripada bit rate berkas yang dilakukan streaming maka akan dianggap baik, meskipun mungkin lebih rendah daripada throughput stream lainnya.

Selain Delay dan Throughput, data lain yang dikumpulkan adalah kekuatan sinyal. Kekuatan sinyal dikumpulkan melalui antena pada smartphone yang terpisah dari smartphone yang melakukan stream. Kekuatan sinyal diukur dengan satuan dBm, menggunakan variabel kontrol jarak bersatuan meter.

Pengujian kekuatan sinyal dilakukan menggunakan perangkat smartphone yang terpisah dari perangkat yang sedang melakukan stream. Hal ini untuk mencegah proses pencatatan data dari mengganggu kapasitas pemrosesan smartphone. Selain itu, pada konfigurasi hotspot tidak dimungkinkan melakukan pengukuran kekuatan sinyal melalui perangkat yang sama, karena perubahan jarak tidak dapat dilakukan antara perangkat klien dengan router WLAN.

Dari data yang dicatat kemudian akan diamati jarak kekuatan sinyal berkurang sebesar $3 \mathrm{~dB}$ terhadap baseline, dengan kata lain jarak yang menyebabkan penurunan kekuatan sinyal sebesar $50 \%$. Hal ini dilakukan karena kebanyakan faktor yang mempengaruhi kekuatan sinyal adalah faktor lingkungan, sehingga untuk jangkauan diluar jarak -3dB tidak ada jaminan bahwa kondisi lingkungan tidak akan mengganggu operasi. - $3 \mathrm{~dB}$ dianggap sebagai titik nyaman dimana kemungkinan tertinggi bagi sinyal dalam sistem untuk melebihi pengaruh faktor lingkungan.

\section{HASIL DAN PEMBAHASAN}

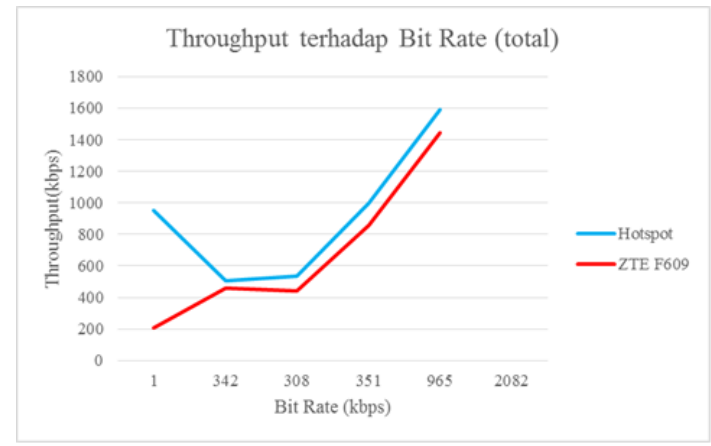

Gambar 2. Grafik perbandingan throughput terhadap bit rate total berkas video

Stream pada kualitas 240s dan 360s berada dalam kapasitas jaringan baik konfigurasi Hotspot maupun ZTE F609, namun kualitas stream tidak memadai di sisi pengguna. Sedangkan stream pada kualitas 1440s dan 2160s berada di luar kapasitas jaringan, ditandai dengan rusaknya citra yang diterima pada klien dan gagalnya stream.

Dengan demikian dapat ditentukan bahwa performa jaringan dan data pada kedua konfigurasi terbaik terjadi pada kualitas stream 1080s dan 720s, karena kedua resolusi berada dalam kapasitas jaringan dan kualitas stream yang didapat cukup jelas di sisi pengguna.

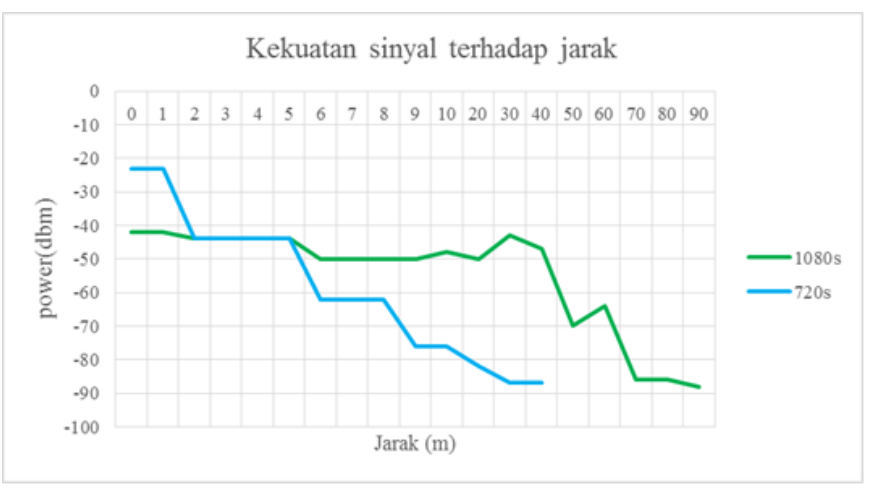

Gambar 3. Grafik pengukuran kekuatan sinyal terhadap jarak.

Pada kualitas stream 1080s, yang dari pengujian sebelumnya ditentukan sebagai kualitas stream optimal, penurunan sebesar $3 \mathrm{~dB}$ dari baseline $-42 \mathrm{dBm}$ ke $-45 \mathrm{dBm}$ terjadi antara jarak $5 \mathrm{dan}$ 6 meter. Jarak kegagalan stream yang terekam pada kualitas ini adalah 85 meter.

Pada kualitas stream 720s, dengan baseline $-23 \mathrm{dBm}$ maka penurunan $-3 \mathrm{~dB}$ terjadi pada kurang dari dua meter, namun dengan baseline $-44 \mathrm{dBm}$ maka penurunan $-3 \mathrm{~dB}$ terjadi antara 5 dan 6 meter. Jarak kegagalan stream yang terekam pada kualitas ini adalah 85 meter.

Asumsi baseline $-44 \mathrm{dBm}$ untuk kualitas 720 s dilakukan oleh peneliti karena baseline tersebut cukup dekat dengan baseline dari stream 1080s, dan karena $-23 \mathrm{dBm}$ merupakan nilai yang peneliti anggap kurang realistis untuk diharapkan selalu terjadi pada jarak 1 meter. Asumsi ini dapat diabaikan, dan desain untuk ruangan dapat dibuat untuk menggunakan repeater dalam jarak jangkauan dua meter. Namun pendapat pribadi peneliti adalah untuk menggunakan jarak jangkauan 5 meter.

Desain ruangan 1 dengan satu antena/pemancar untuk menyambungkan ke server diletakkan pada sudut ruangan. Dengan menggunakan rancangan ini, ruangan yang dihasilkan maksimal berukuran $3 \times 4$ meter, untuk memastikan titik terjauh dari antena/pemancar server berjarak maksimal 5 meter.

Desain ini dibuat dengan mempertimbangkan titik terjauh dari pemancar yang berada di salah satu sudut ruangan, yakni titik sudut ruangan yang berseberangan. Dengan menganggap jarak ini sebagai hipotenusa dari sebuah segitiga siku-siku, dapat ditemukan sisi-sisi lain. Dalam hal ini karena 5 merupakan salah satu bilangan pythagorean triple, dapat segera diketahui bahwa sisi-sisi lain akan berukuran 3 dan 4 meter.

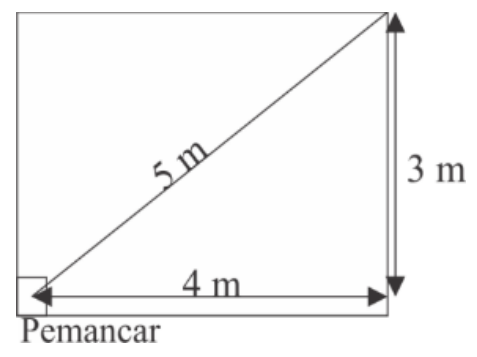

Gambar 4. Rancangan ruangan 1

Desain ruangan 2 dengan satu antena/pemancar server diletakkan di tengah salah satu sisi ruangan. Dengan 
menggunakan rancangan ini, ruangan yang dihasilkan maksimal berukuran $6 \times 4$ meter, untuk memastikan titik terjauh dari antena/pemancar server berjarak maksimal 5 meter.

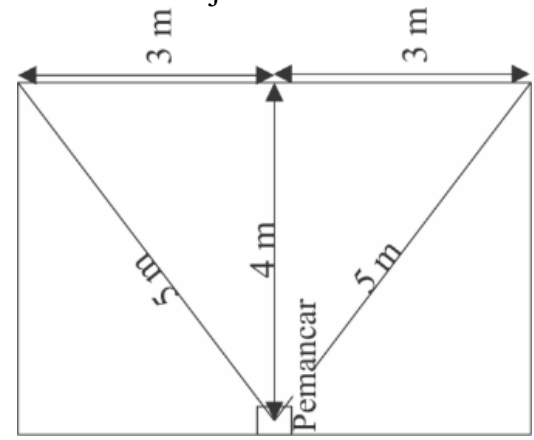

Gambar 5. Rancangan ruangan 2

Desain ruangan 3 dengan dua antena/repeater server diletakkan di dua sudut berlawanan ruang. Dengan menggunakan rancangan ini, ruangan yang dihasilkan maksimal berukuran $5 \times 5$ meter, untuk memastikan setiap titik dalam ruangan maksimal memiliki jarak paling jauh lima meter dari salah satu pemancar.

Jarak antara kedua pemancar dalam rancangan ini adalah kurang lebih sebesar tujuh meter.

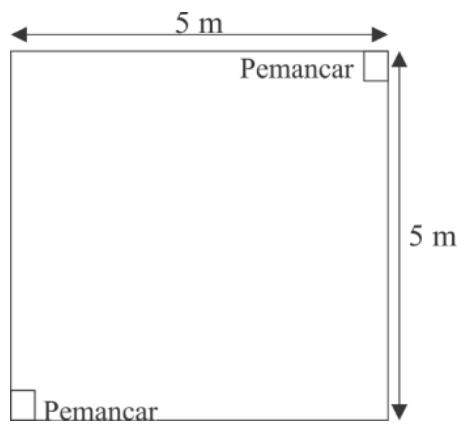

Gambar 6. Rancangan ruangan 3

Desain ruangan 4 dengan dua antena/repeater server diletakkan di dua sisi berlawanan ruang. Dengan menggunakan rancangan ini, ruangan yang dihasilkan maksimal berukuran $6 \times 8$ meter, untuk memastikan setiap titik dalam ruangan maksimal memiliki jarak paling jauh lima meter dari salah satu pemancar.

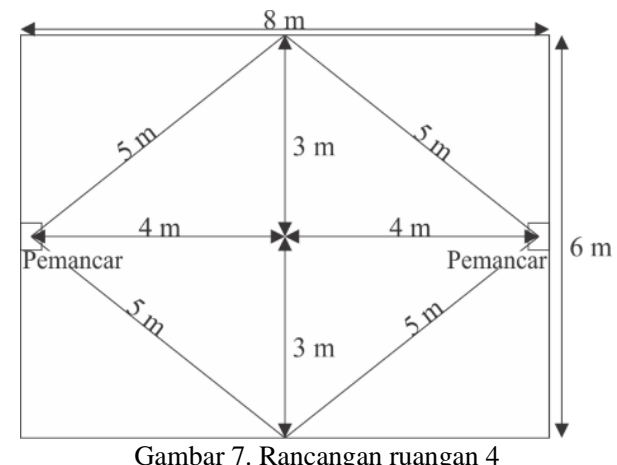

\section{KESIMPULAN}

Sistem virtual reality yang dirancang mampu menggunakan hotspot smartphone untuk melakukan streaming pada resolusi 1080s serta 720 s dengan luas ruangan hingga $6 \times 4$ meter untuk konfigurasi dengan satu pemancar, dan hingga 6x8 meter untuk konfigurasi dengan dua pemancar. Batasan ukuran ruangan ini didasarkan pada titik penurunan kekuatan sinyal sebesar $-3 \mathrm{~dB}$ yang terjadi pada jarak 5 meter pada kedua resolusi, sehingga batasan jarak terjauh antara klien dan server adalah 5 meter.

\section{REFERENSI}

[1] A. Amer dan P. Peralez, "Affordable altered perspectives: Making augmented and virtual reality technology accessible," dalam Global Humanitarian Technology Conference (GHTC), San Jose, 2014.

[2] Google, Inc., "Google Cardboard (I/O 2015) Technical Specification v2.0," 2015. [Online]. Available: https://vr.google.com/cardboard/manufacturer. [Diakses 5 Maret 2018].

[3] J. Postel, “"Internet Protocol - DARPA Internet Program Protocol Specification," RFC 791," University of Southern California Information Sciences Institute, Los Angeles, 1981. 